\title{
Prevention of nosocomial infections in acute respiratory failure patients
}

\begin{abstract}
E. Girou
Prevention of nosocomial infections in acute respiratory failure patients. E. Girou. (C) ERS Journals Ltd 2003.

ABSTRACT: Patients with acute respiratory failure are predisposed to acquire nosocomial infection primarily because they may need ventilatory support, usually invasive mechanical ventilation. The presence of an endotracheal tube impairs natural defences of the respiratory tract and favours airways colonisation and lung infection. Cross transmission of microorganisms may also occur via contaminated hands of healthcare workers that manipulate invasive devices. Thus, avoiding the endotracheal tube and increasing hand hygiene compliance are major measures to prevent ventilatorassociated pneumonia. The use of noninvasive ventilation has been shown to reduce the incidence of nosocomial infections and should be used whenever possible.

Using hand rubbing with waterless alcohol-based products evidenced higher efficacy to reduce hand contamination as compared to conventional hand washing with soap. Due to its rapid activity and ease of access, hand rubbing constitutes a promising avenue for improving hand hygiene compliance and thus reducing cross infection.

Eur Respir J 2003; 22: Suppl. 42, 72s-76s.
\end{abstract}

Correspondence: E. Girou

Unité d'Hygiène et Prévention de l'Infection

Hôpital Henri Mondor

51 avenue du Maréchal De Lattre de

Tassigny

94010 Créteil

France

Fax: 33149814598

E-mail: emmanuelle.girou@hmn.ap-hopparis.fr

\section{Keywords: Hand hygiene} noninvasive ventilation nosocomial infections ventilator-associated pneumonia
Patients with acute respiratory failure (ARF) undergoing mechanical ventilation (MV) are exposed to two kinds of risk factors that predispose them to develop nosocomial infections: the presence of an endotracheal tube which interferes with a number of respiratory tract defence mechanisms and the exposure to cross transmission of microorganisms via the hands of healthcare personnel during manipulation of ventilator-associated devices. Ventilator-associated pneumonia (VAP) is the most common infectious complication that occurs in ARF patients. The pathogenesis of VAP usually requires that two important processes take place: bacterial colonisation of the aerodigestive tract and the aspiration of contaminated secretions into the lower airway. Therefore, the strategies aimed at preventing VAP usually focus on reducing the burden of bacterial colonisation in the aerodigestive tract, decreasing the incidence of aspiration, or both [1, 2]. The Centers for Disease Control and Prevention National Nosocomial Infection Surveillance System (NNIS) reported in 1995-1902 the median rate of VAP per 1000 ventilator-days in NNIS hospitals ranged from 4.3 in respiratory intensive care units (ICUs) to 16.2 in trauma ICUs [3]. Several studies have suggested that the occurrence of nosocomial pneumonia increased the risk of death in critically ill patients, especially when pneumonia episodes were due to high-risk pathogens, such as Acinetobacter or Pseudomonas spp. [4-7].

As pointed out recently in the statement of the 4th International Consensus Conference in Critical Care on ICU-acquired pneumonia, few interventions have shown a benefit in the prevention of VAP [8]. The most promising interventions currently are the avoidance of indiscriminate antibiotic use, limiting stress ulcer prophylaxis to high-risk patients, placing patients in semi-recumbent position, the use of noninvasive ventilation (NIV) whenever feasible and a high compliance to hand hygiene. This article will focus on the last two cited interventions since they seem to decrease not only VAP but nosocomial infections altogether.

\section{Noninvasive positive pressure ventilation}

Invasive medical devices used for the administration of conventional MV are important contributors to the pathogenesis and development of VAP. Especially, artificial airways interfere with a number of respiratory tract defence mechanisms. Endotracheal tubes facilitate bacterial colonisation of the tracheobronchial tree, as well as lower airway aspiration of contaminated secretions. This is due to the association of mucosal lesions, pooling of contaminated secretions above the endotracheal cuff, and elimination of the cough reflex. Regarding the duration of exposure to conventional MV, at least two other studies have shown that the longer the duration of conventional MV, the greater the risk of VAP [9, 10]. More recently, in a study aimed at identifying risk factors for nosocomial pneumonia in different adult critical-care populations, the strongest predictor for VAP in both surgical and medical/respiratory ICU groups of patients was found to be prolonged conventional MV more than one day, resulting in a 12-fold increase in risk over nonventilated patients [11]. Various multivariate analyses have identified ventilatory assistance as an independent risk factor for nosocomial infection [11-18]. Independent risk factors identified in these studies concerned either the use of endotracheal intubation and MV or the duration of ventilatory support in patients undergoing endotracheal intubation. The main conclusion drawn from these studies is that the longer the duration of MV the greater the risk of nosocomial pneumonia. Besides, the magnitude of risk associated with the use of endotracheal intubation ranged from 5.0-7.0.

The increased risk of pneumonia attributable to endotracheal intubation has prompted pulmonologists and intensivists to seek alternative ways of delivering positive-pressure ventilation, i.e. through a face mask, to patients suffering from ARF due to various causes. Several randomised control trials have examined the potential benefit of NIV either as first-line therapy in critically ill patients with ARF from 
various causes (mostly acute hypercapnic respiratory failure) as compared with conventional therapy or to facilitate weaning from MV [19]. The primary endpoints of these trials were mortality rate, intubation rate, duration of mechanical ventilatory support, and length of stay (LOS). In addition of these endpoints, infectious complications such as sepsis, pneumonia and sinusitis, were recorded in most of these trials. Table 1 summarises the ICU-acquired infectious complication rates reported in the randomised controlled trials evaluating the efficacy of NIV.

To date, four cohort or case-control studies have specifically examined the impact of NIV on nosocomial infection rates (table 2). In a prospective cohort study of 360 patients receiving various modalities of $\mathrm{MV}$, GUÉRIN et al. [27] found that the incidence density of pneumonia was 8.5 per 1000 days of endotracheal intubation and 1.6 per 1000 days of NIV. Yet, these results did not take into account the NIV group patients who failed NIV and eventually required endotracheal intubation. When failures of NIV were included in the NIV group for analysis, incidence rates of nosocomial pneumonia were similar between NIV and conventional MV patients. The different severity of patients and etiologies of ARF as well as the high percentage of NIV failures could explain the lack of benefit with NIV on infection rates.

More interesting, another prospective cohort study conducted by NouRDINE et al. [28] showed a markedly lower incidence density of nosocomial infections in 129 patients treated with NIV as compared to 607 patients receiving conventional MV (4.4\%o versus $13.2 \%$ days of MV, $\mathrm{p}<0.05$ ). Furthermore, the overall density of nosocomial infection was reduced two-fold in patients treated with NIV (14.2\%oversus $30.3 \%$ days of $\mathrm{MV}, \mathrm{p}<0.01)$. After adjustment for the admission category, severity and sex, the use of NIV remained associated with a twice-lower risk of infection, while endotracheal intubation was associated with a four-fold higher risk of pneumonia as compared to NIV. As expected, nosocomial infections were associated with a higher utilisation of invasive devices (endotracheal tube, urinary catheter and intravascular catheter) and a longer ICU stay, whereas the use of NIV was associated with lesser utilisation of invasive devices.

Table 1.-Infectious complication rates reported in randomised controlled trials on noninvasively ventilated (NIV) patients

\begin{tabular}{lclll}
\hline 1st author [ref no.] & Year of study & NIV & Controls & p-value \\
\hline BROCHARD [20] & 1995 & $4 / 43(9)$ & $10 / 42(24)$ & 0.08 \\
KRAMER [21] & 1995 & $5 / 16(31)$ & $11 / 15(73)$ & 0.02 \\
ANTONELLI [22] & 1998 & $1 / 32(3)$ & $10 / 32(31)$ & 0.008 \\
WOOD [23] & 1998 & $3 / 16(19)$ & $3 / 11(27)$ & 0.66 \\
CONFALONIERI [24] & 1999 & $0 / 28(0)$ & $5 / 28(18)$ & 0.05 \\
ANTONELLI [25] & 2000 & $3 / 20(15)$ & $7 / 20(36)$ & 0.27 \\
NAVA [26] & 1998 & $0 / 25(0)$ & $7 / 25(28)$ & 0.01 \\
\hline
\end{tabular}

Data are presented as $\mathrm{n} /$ total $\mathrm{n}(\%)$.
A prospective observational survey was recently performed over 3 weeks among 42 French ICUs to assess the incidence of use and effectiveness of NIV in everyday clinical practice [29]. Ventilatory assistance was required in 689 patients with ARF, 581 with conventional MV and $108(16 \%)$ with NIV. The incidence of nosocomial pneumonia was lower in patients treated with NIV. Success of NIV was associated with a lower risk of pneumonia (odds ratio (OR) 0.06; 95\% confidence interval (CI) $0.01-0.45$ ) and of death (OR 0.16 ; 95\% CI 0.05-0.54). Conversely, failure of NIV was not a risk factor for nosocomial pneumonia, but was associated with longer length of stay and MV.

Recently, a case-control study was performed to compare outcomes for similar patients admitted for acute exacerbations of chronic obstructive pulmonary disease or severe cardiogenic pulmonary oedema that were treated with NIV or received endotracheal intubation and conventional MV [30]. The main objective was to determine whether the use of NIV was associated with a decreased risk of nosocomial infections in everyday clinical practice in patients for whom the benefit of NIV had been clearly demonstrated in randomised clinical trials. A careful matching process was used to avoid selecting more seriously ill patients in the conventional MV group. Rates of nosocomial infections and nosocomial pneumonia were significantly lower in patients who received NIV than those treated with MV. Similarly, the daily risk of acquiring an infection, mean duration of ventilation, mean LOS and crude mortality ( $4 \%$ versus $26 \%, \mathrm{p}=0.002$ ) were all lower in the NIV group.

Critically ill patients treated with NIV are less likely to acquire pneumonia and other nosocomial infections than similar patients treated with conventional MV. This benefit has been shown in several randomised controlled trials and has been confirmed out of the context of a randomised trial, in actual clinical practice, in prospective cohort studies and one case-control study to date. Moreover, conducting further randomised controlled trials to especially assess the effect of NIV on occurrence of nosocomial infections might be ethically questionable regarding the weight of evidence supporting the benefit of NIV in patients with hypercapnic respiratory failure $[31,32]$. The impact of NIV not only on pneumonia but also on other sites of ICU-acquired infections appears to be linked to an avoidance or at least a shortened exposure to well-known risk factors for nosocomial infection, such as duration of invasive procedures and length of ICU stay. Furthermore, the benefit of NIV on infectious complications will depend on the success rate of the technique in the population studied. The careful selection of patients eligible for NIV (i.e. with no contraindications to NIV such as respiratory arrest, hypotensive shock, impaired cough or swallowing mechanism, coma or agitation) is therefore important to achieve a beneficial effect on nosocomial infections. Education programs for optimal delivery of NIV (choice of proper site for initiation, choice of ventilator, interface and initial settings) should also be a priority because its use may not be successful in all hands.

Table 2.-Nosocomial infection rates reported in cohort and case-control studies on noninvasively ventilated (NIV) patients

\begin{tabular}{lccrrr}
\hline 1st author [ref no.] & Year of study & \multicolumn{2}{c}{ Nosocomial pneumonia } & & \multicolumn{2}{c}{ Nosocomial infections } \\
\cline { 3 - 4 } & & NIV & CMV & NIV \\
\hline GUÉRIN [27] & 1997 & $8 / 98(8)$ & $15 / 199(8)$ & NA & NA \\
CARLUCCI [29] & 2001 & $11 / 108(10)$ & $72 / 380(19)$ & NA & NA \\
NOURDINE [28] & 1999 & $4 / 154(3)$ & $80 / 607(13)$ & $27 / 154(18)$ & $218 / 607(36)$ \\
GIROU [30] & 2000 & $4 / 50(8)$ & $11 / 50(22)$ & $9 / 50(18)$ & $30 / 50(60)$ \\
\hline
\end{tabular}

Data are presented as n/total n (\%). CMV: conventional mechanical ventilation; NA: not available. 


\section{Cross-infection via hands of personnel}

Pathogens causing nosocomial pneumonia and other nosocomial infections, such as Gram-negative bacilli and Staphylococcus aureus, are ubiquitous in healthcare settings, especially in intensive or critical care areas [33]. Transmission of these microorganisms to patients frequently occurs via the hands of healthcare personnel that become contaminated or transiently colonised with the microorganisms [34]. Procedures such as tracheal suctioning and manipulation of ventilator circuit or endotracheal tubes increase the opportunity for cross-contamination. Using aseptic technique and sterile or disinfected equipment when appropriate and eliminating pathogens from the hands of personnel can reduce the risk of cross-contamination [8]. Hand hygiene is widely recognised as an important but underused measure to prevent nosocomial infections [34]. Even if hand hygiene seems the simplest method of prevention, all studies that have examined hand-washing practices for $20 \mathrm{yrs}$ report great difficulties in obtaining a good compliance to this measure. New guidelines that promote the use of hand rubbing with a waterless alcohol-based product have been recently published and may increase personnel compliance and decreased incidence of hand-transmitted infections [35].

Several experimental assays approaching real conditions of use have examined the relative efficacy of hand hygiene techniques to remove microorganisms from hands. All showed a poor bactericidal activity of hand washing with nonmedicated soap as compared with hand hygiene with antiseptic agents [35]. To date, only five clinical studies have evaluated the efficacy of hand hygiene procedures in routine practice [36-40]. In a prospective, randomised clinical trial, ZARAGOZA et al. [40] compared the efficacy of an alcoholic solution with hand washing with nonmedicated soap during regular work in clinical wards and ICUs of a large public university hospital in Barcelona. Healthcare workers were randomly assigned to hand washing or hand rubbing with the alcoholic solution by using a crossover design. The average reduction in the number of colony-forming units from samples before hand washing to samples after hand washing was $50 \%$ for hand washing and $88 \%$ for hand rubbing. When both methods were compared, the average number of colonyforming units recovered after the procedure showed a statistically significant difference in favour of the alcoholic solution $(\mathrm{p}<0.001)$. PITTET et al. [39] performed an uncontrolled observational study to examine the process of bacterial contamination of healthcare workers' hands during routine patient care in a large teaching hospital. Trained external observers conducted structured observations of 417 episodes of care. Respiratory care was a care activity independently associated with higher contamination levels. Simple hand washing with nonmedicated soap before patient care, without hand antisepsis, was also associated with significantly higher colony counts. LARSON et al. [37] performed a randomised clinical trial to compare skin condition and skin microbiology among 50 ICU personnel using one of two randomly assigned hand hygiene regimens: hand washing with an antiseptic soap or hand rubbing with an alcohol-based gel. Each hand hygiene regimen was assigned for four consecutive weeks. Hand cultures $(n=193)$ were obtained four times: at baseline, during the first day of week 1 , and as late as possible on the subject's last workday of weeks 2 and 4 . For the handwashing group, there were no significant differences between baseline mean $\log$ counts and mean log counts from day 1 , week 2, or week 4. For the hand-rubbing group, counts were significantly lower than baseline at day 1 and week 2 , but not week 4. In a crossover clinical trial, LUCET et al. [38] did not find a significant difference in bacterial counts between antiseptic hand washing and hand rubbing. Another randomised controlled trial compared the efficacy of hand rubbing with an alcohol-based solution versus conventional hand washing with antiseptic soap in reducing hand contamination during routine ICU patient care [36]. During daily nursing sessions of $2-3 \mathrm{~h}, 23$ healthcare workers were randomly assigned to either hand rubbing with alcohol-based solution or hand washing with antiseptic soap when hand hygiene was indicated before and after patient care. With hand rubbing the median percentage reduction in bacterial contamination was significantly higher than with hand washing ( $83 \%$ versus $58 \%, \mathrm{p}=0.012$ ), with a median difference in the percentage reduction of $26 \%(95 \%$ CI $8-44 \%)$.

With regard to this body of data coming from either experimental or clinical studies, hand rubbing with an alcohol-based product appears to be the best method to achieve hand disinfection.

Studies evaluating the impact of hand hygiene on nosocomial infection rates examine generally all sites of infection together. In some studies, the results are detailed according to the site of infection, but, usually, they are not powered enough to evidence significant difference by site of infection. Most of the studies presented below took advantage of the discovery of poor hand hygiene practices to evaluate interventions aimed at increasing hand hygiene compliance and monitored in parallel nosocomial infection rates. Such studies are very difficult to perform because the duration of follow-up has to be long to see both increase of compliance and decrease of infections.

With a sequential intervention study in an ICU, CONLY et al. [41] demonstrated that poor hand-washing practices were associated with a high nosocomial infection rate, whereas good hand-washing practices were associated with a low nosocomial infection rate. An educational program designed to improve hand-washing procedures significantly reduced endemic nosocomial infection rates. Before the educational program, the nosocomial infection rate (number of infections per 100 patient discharges) was $>30 \%$ with hand-washing compliance of $14 \%$ and $28 \%$ before and after patient contact, respectively. After the institution of the first educational program, the infection rate decreased dramatically to $12 \%$ meanwhile hand-washing compliance rates reached $73 \%$ and $81 \%$ before and after contact. The infection rates were maintained at a low level during the following 3 yrs. The fourth year, nosocomial infection rates increased to $33 \%$ with poor hand-washing practices $(26 \%$ and $23 \%$ before and after contact, respectively). A second educational program was implemented, and nosocomial rates dropped again to $9 \%$ with average hand-washing compliance of $60 \%$.

Hand washing and infection rates were studied in two ICUs of a community teaching hospital [42]. Hand washing rates were monitored secretly throughout the study. After six months of observation, educational interventions were started to increase hand washing. Hand washing increased gradually, but overall compliance rates before $(22 \%)$ and after $(30 \%)$ interventions were not significantly different $(\mathrm{p}=0.07)$ whereas infection rates per 100 admissions remained stable $(22 \%$ and $23 \%$ ).

For eight months, DoebBeling et al. [43] conducted a prospective multiple-crossover trial involving 1894 adult patients in three ICUs. In a given month, the ICU used a hand-washing system involving either chlorhexidine, or alcohol with the optional use of a nonmedicated soap; in alternate months the other system was used. Rates of nosocomial infection and hand-washing compliance were monitored prospectively. When chlorhexidine was used, there were 152 nosocomial infections, as compared with 202 when the combination of alcohol and soap was used (adjusted incidence-density ratio $0.73 ; 95 \%$ CI $0.59-0.90)$. The largest 
reduction with chlorhexidine was in gastrointestinal infections. However, because only a minimal amount of the alcohol rinse was used during periods when the combination regimen was also in use and because compliance with handwashing instructions was higher when chlorhexidine was available $(48 \%$ versus $30 \%, \mathrm{p}=0.002)$, determining which factor (i.e. the hand-hygiene regimen or differences in adherence) accounted for the lower infection rates was difficult.

More recently, PITTET et al. [44] attempted to promote hand hygiene by implementing a hospital-wide program, with special emphasis on bedside, alcohol-based hand disinfection and measuring nosocomial infections in parallel. The overall compliance with hand hygiene during routine patient care in a teaching hospital in Geneva was monitored before and during implementation of a hand-hygiene promoting campaign. Seven hospital-wide prevalence surveys were done twice yearly from December 1994, to December 1997. Secondary outcome measures were nosocomial infection rates, attack rates of methicillin-resistant Staphlococcus aureus (MRSA), and consumption of hand rub disinfectant. Compliance with hand hygiene improved progressively from $48 \%$ in 1994 , to $66 \%$ in $1997(\mathrm{p}<0.001)$. During the same period, overall nosocomial infection decreased (prevalence of $17 \%$ in 1994 to $10 \%$ in 1998; $\mathrm{p}=0.04)$, and MRSA transmission rates decreased (2.16 to 0.93 episodes per 10,000 patient-days; $\mathrm{p}<0.001)$.

There is a good level of evidence showing that hand hygiene with antiseptic products is effective to significantly reduce hand contamination during patient care activities. Surely, the best technique is hand rubbing with an alcohol-based solution. This measure should decrease the risk of cross transmission of microorganisms and thus decrease the risk of acquiring an infection, especially in intensive care unit patients.

\section{References}

1. Cook D, De Jonghe B, Brochard L, Brun-Buisson C. Influence of airway management on ventilator-associated pneumonia. JAMA 1998; 279: 781-787.

2. Kollef MH. The prevention of ventilator-associated pneumonia. N Engl J Med 1999; 340: 627-633.

3. CDC NNIS System. National Nosocomial Infections Surveillance (NNIS) system report, data summary from January 1992-June 2001, Issued August 2001. Am J Infect Control 2001; 29: $404-421$.

4. Bueno-Cavanillas A, Delgado-Rodriguez M, Lopez-Luque A, Schaffino-Cano S, Galvez-Vargas R. Influence of nosocomial infection on mortality rate in an intensive care unit. Crit Care Med 1994; 22: 55-60.

5. Fagon JY, Chastre J, Vuagnat A, Trouillet JL, Novara A, Gibert C. Nosocomial pneumonia and mortality among patients in intensive care units. JAMA 1996; 275: 866-869.

6. Fagon JY, Chastre J, Domart Y, Trouillet JL, Gibert C. Mortality due to ventilator-associated pneumonia or colonization with Pseudomonas and Acinetobacter species: assessment by quantitative culture of samples obtained by a protected specimen brush. Clin Infect Dis 1996; 23: 538-542.

7. Kollef MH, Silver P, Murphy DM, Trovillion E. The effect of late-onset ventilator-associated pneumonia in determining patient mortality. Chest 1995; 108: 1655-1662.

8. Hubmayr RD. Statement of the 4th international consensus conference in critical care on ICU-acquired pneumonia - Chicago, Illinois, May 2002. Intensive Care Med 2002; 28 : 1521-1536.

9. Fagon JY, Chastre J, Domart Y, et al. Nosocomial pneumonia in patients receiving continuous mechanical ventilation. Am Rev Respir Dis 1989; 139: 877-884.
10. Langer M, Mosconi P, Cigada M, Mandelli M the Intensive Care Unit Group of Infection Control. Long-term respiratory support and risk of pneumonia in critically ill patients. Am Rev Respir Dis 1989; 140: 302-305.

11. Cunnion KM, Weber DJ, Broadhead WE, Hanson LC, Pieper CF, Rutala WA. Risk factors for nosocomial pneumonia: comparing adult critical-care populations. $\mathrm{Am}$ J Respir Crit Care Med 1996; 153: 158-162.

12. Torres A, Aznar R, Gatell JM, et al. Incidence, risk and prognosis factors of nosocomial pneumonia in mechanically ventilated patients. Am Rev Respir Dis 1990; 142: 523-528.

13. Hanson LC, Weber DJ, Rutala WA. Risk factors for nosocomial pneumonia in the elderly. Am J Med 1992; 92: 161-166.

14. Celis R, Torres A, Gatell JM, Almela M, Rodriguez-Roisin R, Agusti-Vidal A. Nosocomial pneumonia: a multivariate analysis of risk and prognosis. Chest 1988; 93: 318-324.

15. Memish ZA, Cunningham G, Oni GA, Djazmati W. The incidence and risk factors of ventilator-associated pneumonia in a Riyadh hospital. Infect Control Hosp Epidemiol 2000; 21: 271-273.

16. Cook DJ, Walter SD, Cook RJ, et al. Incidence of and risk factors for ventilator-associated pneumonia in critically ill patients. Ann Intern Med 1998; 129: 433-440.

17. van der Sar-van der Brugge S, Arend SM, Bernards AT, et al. Risk factors for acquisition of Serratia marcenscens in a surgical intensive care unit. J Hosp Infect 1999; 41: 291-299.

18. Vanhems P, Lepape A, Savey A, Jambou P, Fabry J and collaborators of the REA Sud-Est Study Group. Nosocomial pulmonary infection by antimicrobial-resistant bacteria of patients hospitalized in intensive care units: risk factors and survival. J Hosp Infect 2000; 45: 98-106.

19. Brochard L. Noninvasive ventilation in acute respiratory failure. JAMA 2002; 288: 932-935.

20. Brochard L, Mancebo J, Wysocki M, et al. Noninvasive ventilation for acute exacerbations of chronic obstructive pulmonary disease. $N$ Engl J Med 1995; 333: 817-821.

21. Kramer N, Meyer TJ, Meharg J, Cece RD, Hill NS. Randomized, prospective trial of noninvasive positive pressure ventilation in acute respiratory failure. Am J Respir Crit Care Med 1995; 151: 1799-1806.

22. Antonelli M, Conti G, Rocco M, et al. A comparison of noninvasive positive-pressure ventilation and conventional mechanical ventilation in patients with acute respiratory failure. N Engl J Med 1998; 339: 429-435.

23. Wood KA, Lewis L, Von Harz B, Kollef MH. The use of noninvasive positive pressure ventilation in the emergency department: results of a randomized clinical trial. Chest 1998; 113: 1339-1346.

24. Confalonieri M, Potena A, Carbone G, Della Porta R, Tolley EA, Meduri GU. Acute respiratory failure in patients with severe community-acquired pneumonia: a prospective randomized evaluation of noninvasive ventilation. $\mathrm{Am}$ J Respir Crit Care Med 1999; 160: 1585-1591.

25. Antonelli M, Conti G, Bufi M, et al. Noninvasive ventilation for treatment of acute respiratory failure in patients undergoing solid organ transplantation. A randomized trial. JAMA 2000; 283: 235-241.

26. Nava S, Ambrosino $\mathrm{N}$, Clini E, et al. Noninvasive mechanical ventilation in the weaning of patients with respiratory failure due to chronic obstructive pulmonary disease. Ann Intern Med 1998; 128: 721-728.

27. Guérin C, Girard R, Chemorin C, De Varax R, Fournier G. Facial mask noninvasive mechanical ventilation reduces the incidence of nosocomial pneumonia. A prospective epidemiological survey from a single ICU. Intensive Care Med 1997; 23: 1024-1032.

28. Nourdine K, Combes P, Carton MJ, Beuret P, Cannamela A, Ducreux JC. Does noninvasive ventilation reduce the ICU nosocomial infection risk? A prospective clinical survey. Intensive Care Med 1999; 25: 567-573.

29. Carlucci A, Richard JC, Wysocki M, Lepage E, Brochard L, 
and the SRLF Collaborative Group on Mechanical Ventilation. Noninvasive versus conventional mechanical ventilation. An epidemiologic survey. Am J Respir Crit Care Med 2001; 163: 874-880.

30. Girou E, Schortgen F, Delclaux C, et al. Association of noninvasive ventilation with nosocomial infections and survival in criticaly ill patients. JAMA 2000; 284: 23612367.

31. Mehta S, Hill NS. Noninvasive ventilation. Am J Respir Crit Care Med 2001; 163: 540-577.

32. Evans TW. International Consensus Conferences in Intensive Care Medicine: non-invasive positive pressure ventilation in acute respiratory failure. Organised jointly by the American Thoracic Society, the European Respiratory Society, the European Society of Intensive Care Medicine, and the Societe de Reanimation de Langue Francaise, and approved by the ATS Board of Directors, December 2000. Intensive Care Med 2001; 27: 166-178.

33. Alberti C, Brun-Buisson C, Burchardi H, et al. Epidemiology of sepsis and infection in ICU patients from an international multicentre cohort study. Intensive Care Med 2002; 28: 108-121.

34. Pittet D, Boyce JM. Hand hygiene and patient care: pursuing the Semmelweis legacy. Lancet Infect Dis 2001; 1: 9-20.

35. Centers for Disease Control and Prevention. Guideline for hand hygiene in health-care settings: Recommendations of the Healthcare Infection Control Practices Advisory Committee and the HICPAC/SHEA/APIC/IDSA Hand Hygiene Task Force. MMWR 2002; 51.

36. Girou E, Loyeau S, Legrand P, Oppein F, Brun-Buisson C. Efficacy of handrubbing with an alcohol-based solution versus standard handwashing with an antiseptic soap. A randomised clinical trial. BMJ 2002; 325: 362-366.

37. Larson EL, Aiello AE, Bastyr J, et al. Assessment of two hand hygiene regimens for intensive care unit personnel. Crit Care Med 2001; 29: 944-951.

38. Lucet JC, Rigaud MP, Mentre F, et al. Hand contamination before and after different hand hygiene techniques: a randomized clinical trial. J Hosp Infect 2002; 50: 276-280.

39. Pittet D, Dharan S, Touveneau S, Sauvan V, Perneger TV. Bacterial contamination of the hands of hospital staff during routine patient care. Arch Intern Med 1999; 159: 821-826.

40. Zaragoza M, Sallés M, Gomez J, Bayas JM, Trilla A. Handwashing with soap or alcoholic solutions? A randomized clinical trial of its effectiveness. Am J Infect Control 1999; 27: 258-261.

41. Conly JM, Hill S, Ross J, Lertzman J, Louie TJ. Handwashing practices in an intensive care unit: the effects of an educational program and its relationship to infection rates. Am J Infect Control 1989; 17: 330-339.

42. Simmons B, Bryant J, Neiman K, Spencer L, Arheart K. The role of handwashing in prevention of endemic intensive care unit infections. Infect Control Hosp Epidemiol 1990; 11: 589594.

43. Doebbeling BN, Stanley GL, Sheetz CT, et al. Comparative efficacy of alternative hand-washing agents in reducing nosocomial infections in intensive care units. $N$ Engl J Med 1992; 327: 88-93.

44. Pittet D, Hugonnet S, Harbath S, et al. Effectiveness of a hospital-wide programme to improve compliance with hand hygiene. Lancet 2000; 356: 1307-1312. 